\title{
E-GOV E SUA IMPORTÂNCIA NA DESBUROCRATIZAÇÃO ADMINISTRAÇÃO PÚBLICA
}

\author{
Ulisses de Melo Furtado \\ Concluinte de Sistemas de Informação na Faculdade de Ciências e Tecnologia Mater Christi - \\ Orientando. E-mail: ulissesmelo11@yahoo.com.br \\ Kleber Jacinto \\ Docente do Curso de Sistemas de Informação na Faculdade de Ciências e Tecnologia Mater \\ Christi - Orientador. E-mail: kleberjacinto@gmail.com
}

\begin{abstract}
RESUMO
A utilização das tecnologias da informação e comunicação são parte da vida da sociedade globalizada. Nesse sentido a Administração Pública passou por uma evolução natural frente aos novos tempos. Toda a burocracia e ineficiência presentes nos serviços públicos tiveram que evoluir e o Governo Eletrônico caracteriza-se como a expressão dessa nova era, pois, tem entre seus objetivos a oferta de serviços eficientes, transparentes e seguros aos cidadãos - que passam a ser postos em lugar de destaque - como também melhorar a relação com as empresas e com as demais esferas e poderes do governo. Diante dessa nova realidade, muitas são as ações já executadas, o que gera um ganho positivo para todos os envolvidos no processo de amadurecimento do E-gov a nível de Brasil. Projetos que visam facilitar o acesso as tecnologias para a população em massa, informatizar escolas e comunidades rurais, como também desburocratizar os processos da gestão, proporcionar mecanismos que garantam a transparência das ações do governo, possibilitando a sociedade verificar regularmente essas informações; renovando também as formas de trabalho e rotinas dos servidores públicos espalhados pelo país, otimizando seus serviços através de sistemas inovadores. É objeto deste estudo conceituar E-gov e expor exemplos de ações em execução nesta área, que prezam pela transparência, eficiência e segurança, inserindo a Administração Pública em uma nova fase.
\end{abstract}

PALAVRAS-CHAVE: Administração Pública, Tecnologia da Informação e Governo Eletrônico

\section{E-GOV AND ITS IMPORTANCE FOR NOT BUREAUCRACY OF PUBLIC ADMINISTRATION}

\begin{abstract}
The use of the technologies of the information and communication are part of the life in a globalized society. In this sense, the Administration has gone through a natural evolution to the new times ahead. All the bureaucracy and inefficiency in public services had to evolve and the Electronic Government characterizes itself as the expression of this new era, therefore, it has among its objectives to offer the provision of efficient, transparent and safe services to the citizens - who are being put in prominent place - as well as improving the relationship with business and other spheres and branches of the government. Facing this new reality, many actions are already implemented, which generates a positive gain for everyone involved in the ripening process of E-government at the level of Brazil. Projects that aim to facilitate access technologies for the mass population, computerize schools and rural communities, but also reduce the bureaucracy of management processes, providing
\end{abstract}


mechanisms to ensure the transparency of the government actions enabling the company to verify this information regularly and renewing also forms of work and routines of public servants across the country optimize their services through innovative systems. It is the object of this study conceptualizes E-gov and exposing examples of running actions in this area, which have the transparency, efficiency and safety by entering the Public Administration in a new phase.

KEY-WORDS: Public Administration, Technology of the information and Electronic Government 


\section{E-GOV E SUA IMPORTÂNCIA NA DESBUROCRATIZAÇÃO ADMINISTRAÇÃO PÚBLICA}

\section{INTRODUÇÃO}

A sociedade está inserida em um mundo globalizado, onde as informações tornaram-se preponderantes para que as organizações mantenham seus lugares no mercado competitivo que estão submetidas.

Nesse sentido, as Tecnologias de Informação e Comunicação - TIC'S tornaram-se intrínsecas em todos os processos das empresas. Sistemas de Informação passaram a ocupar lugar de destaque, muitas vezes, sendo o responsável pelo diferencial competitivo que a organização detém sobre as concorrentes, seja diminuindo custos na fase de produção, possibilitando a fabricação do produto de forma mais eficiente, otimizando rotinas, ou ainda, fornecendo dados relevantes para tomada de decisões.

Todos esses benefícios são gerados através dos diversos tipos de sistemas de informação disponíveis, a saber: sistemas de comércio eletrônico, sistema de processamento de transações, sistema de informação gerencial, sistemas de apoio a decisão, sistemas especialistas, sistemas de inteligência artificial e sistemas de realidade virtual. Todos estes, dependendo do ramo de atuação da organização e dos objetivos almejados por esta, agem buscando aperfeiçoar os processos a que se propõem realizar.

No momento em que as organizações privadas passaram por uma transformação tecnológica, inserindo as TIC's em seu cotidiano, a Administração Pública também teve que renovar-se, atendendo às exigências naturais de uma nova era, onde a correta manipulação das informações tornou-se fator fundamental ao sucesso, inclusive, para os órgãos públicos.

A Administração Pública, sempre relacionada a serviços ineficientes e burocráticos, tendo ainda que cumprir inúmeras exigências legais, como os princípios básicos, citados explicitamente na Constituição Federal de 1988, a saber: legalidade, impessoalidade, moralidade, publicidade e eficiência. Todas essas exigências, necessárias para evitar desvio de recursos públicos, tornavam os processos ainda mais complexos e lentos.

Surge então o Governo Eletrônico - E-gov, definido por Guilarducci (2007, p. 18) como "o uso das tecnologias da informação e comunicação para garantir o cumprimento efetivo e eficiente dos princípios que legitimam o Governo constituída para o povo, ou seja, é o uso das TIC'S para o cumprimento real das Leis que regem a nação".

O E-gov apresenta-se como uma alternativa quando se pretende otimizar os serviços públicos de forma eficiente, segura e transparente, melhorando as relações dos governos com os cidadãos, com as empresas e com outras esferas e poderes da administração, facilitando o cumprimento dos princípios básicos da administração pública e, ao mesmo tempo eliminando a burocracia que impedia a agilidade dos serviços, preservando a segurança e transparência na utilização dos recursos públicos. Nessa perspectiva, desde o ano 2000, diversas ações e projetos vêm sendo desenvolvidos buscando melhorar a gestão pública através do E-gov.

Diante dessa nova realidade em que a administração pública está inserida através do E-gov, busca-se como objetivos principais deste estudo, conhecer essa nova realidade, descrevendo suas origens no Brasil, estágios e tipos de serviços oferecidos, explanando ainda, casos de sucesso que já renovam os serviços públicos em alguns setores beneficiados, com ações inovadores, seguras e eficientes. 
A administração pública, com toda a sua complexidade e estrutura, tem a possibilidade de encontrar no E-gov uma oportunidade de renovar-se e por esse motivo, tem investido em novas ações que utilizam TIC's, tornando-se um mercado propício a ser desbravado e estudado. Assim, este trabalho justifica-se por expor acerca da importância do E-gov para a sociedade, para as empresas, para os próprios governos e, também, para os profissionais de TI, que podem direcionar suas potencialidades para a área pública em todas as suas divisões.

\section{ADMINISTRAÇÃO PÚBLICA}

A Administração Pública, seja a nível Municipal, Estadual ou Federal tem sua definição e abrangência ampla, tendo em vista as responsabilidades e competências necessárias ao exercício desta. Questões sociais, culturais, econômicas e políticas devem ser observadas pelos agentes públicos. A Gestão Pública possui varias definições devido à sua complexidade e ao alcance da sua área de atuação. Segundo Meirelles (2004, p. 63), "Numa visão global, a Administração Pública é todo aparelhamento do Estado preordenado à realização de serviços, visando a satisfação das necessidades coletivas". Neste aspecto, através dos recursos do Estado deve-se realizar serviços para melhorar a qualidade de vida das pessoas, ou seja, a coletividade. Medauar (2000, p. 43) explana seu pensamento acerca deste tema enfatizando que o mesmo representa o conjunto de órgãos e entes estatais que produzem serviços, bens e utilidades para a população.

Baseado nestas definições percebe-se uma busca para satisfazer a coletividade através de uma organização do Estado de forma estruturada, sendo um conjunto de ações inter-relacionadas e serviços em prol da satisfação dos anseios da comunidade no tocante a saúde, segurança, educação e qualidade de vida.

A Administração Pública, ainda, pode ser classificada segundo Seresuela (2002) como: Administração Direta, quando exercida pelos órgãos internos, ou seja, Presidência e Ministros; Governador e Secretários de Estado; Prefeito e Secretários Municipais ou Administração Indireta quando exercida por outros órgãos do Estado surgidos devido a necessidade e ao aumento da atuação do Estado. Façam parte deste grupo as autarquias, empresas públicas, fundações, sociedade de economia mista, etc.

\section{ORGANIZAÇÃO POLÍTICO-ADMINISTRATIVA}

Tomando por base todos os conceitos acerca da Administração Pública, torna-se importante conhecer a divisão político-administrativa do Brasil de acordo com a Constituição Federal de 1988, pois, dessa forma, é possível entender como o país está estruturado e os limites de atuação de cada esfera e poder do governo.

\section{ESFERAS DE GOVERNO}

O sistema de governo vigente no país caracteriza-se por uma República Presidencialista onde um Presidente é eleito democraticamente pelo povo. Os Poderes Legislativo, Judiciário e Executivo são independentes e os mandatos dos gestores têm prazos definidos, estes, na verdade estão representando os anseios do povo. (ALEXANDRINO e PAULO, 2009)

Dessa forma as esferas de Governo partem da base do Estado que, segundo Moraes (2009, p. 03) "é a forma histórica de organização jurídica limitado a um determinado território e com população definida e dotado de soberania de governo". Nesse contexto, constata-se que há 
três elementos no Estado que são inseparáveis, ou seja, este só existe quando está presente o povo, o território e um governo soberano.

A Constituição de 1988 definiu o Estado Federado como vigente no país, este caracteriza-se pela descentralização política, onde em um mesmo território dividido por regiões, diferentes níveis de governo possam atuar, tendo autonomia por sua organização, legislação, administração e governo em uma determinada localidade ou região do país.

Os Municípios se caracterizam como um poder político local e estão presentes em territórios dentro de um Estado, possuem também autonomia por sua legislação, administração, organização e governo.

O Distrito Federal, representado por Brasília, é caracterizado por Estado e Município, ou seja, possui poder político regional e local concomitantemente.

A junção dos entes federados: Municípios, Estados e o Distrito Federal espalhados pelas diversas regiões do país formam a União, ou República Federativa do Brasil que é o poder político central do país. O Governo Federal é quem gerencia toda a Nação de forma eficiente e organizada.

As esferas de governo definidas segundo Alexandrino e Paulo (2009, p. 14) são:

\begin{tabular}{|l|l|}
\hline NÍVEL & CARACTERISTICAS \\
\hline União & Poder político central - Gerencia todo o território nacional. \\
\hline Estados & Poder político regional - Gerencia determinada região do país. \\
Município & Poder político municipal - Gerencia uma comunidade local. \\
Distrito Federal & Poder político regional e municipal - Capital do país: Brasília. \\
\hline & $\begin{array}{l}\text { QUADRO 01 - Esferas do Governo Brasileiro. } \\
\text { Adaptado de Alexandrino e Paulo (2009, p. 14) }\end{array}$
\end{tabular}

Diante dessas considerações, observa-se como o Brasil está subdivido administrativamente, onde cada uma das esferas têm sua independência preservada, possuindo autonomia administrativa, financeira e política. Contudo, observa-se um trabalho caracterizado pela coordenação entre os diferentes níveis de governo, sendo estes caracterizados como Administração Pública e devendo cumprir os seus princípios constitucionais vigentes.

\section{OS TRÊS PODERES}

A organização político-administrativa do Brasil, busca impedir a concentração de poder em apenas uma pessoa ou órgão. A Constituição Federal de 1988 em seu Artigo $2^{\circ}$ descreve: "são Poderes da União, independentes e harmônicos entre si, o Legislativo, o Executivo e o Judiciário".

O Poder Executivo tem como função executar as ações diretas para a coletividade, isto é, exercer a função administrativa de fato, sendo a União representada pelo Presidente da República, nos Estados pelos Governadores e nos Municípios pelos Prefeitos. Todos estes dentro dos limites do seu ente federado devem exercer com eficiência as funções de administrador público, cumprindo e seguindo a legislação local, estaduais e federais, destacando ainda, os princípios constitucionais básicos já expostos. 
O Poder Legislativo é representado pela Assembléia Legislativa no Governo Federal, pelas Câmaras dos Deputados, seja Federal, Estadual ou Distrital e ainda pela Câmara dos Vereadores Municipais. A função deste Poder é atualizar as novas leis, gerenciando-as, além de poderem criar novas leis de acordo com as necessidades da sociedade e do próprio executivo, aprovando ainda projetos e propostas do governo que dependem legalmente de sua análise.

O Poder Judiciário tem como funções principais esclarecer dúvidas surgidas na interpretação das Leis, baseado sempre na própria legislação; é responsável ainda, por julgamentos, estando presente desde o nível municipal, passando pelo Estadual e tendo seu grau mais elevado na escola Federal.

Todos os Poderes são independentes, porém, são flexíveis ao ponto que exercem suas funções típicas e rotineiras, podendo ainda executar funções atípicas (funções típicas de outro poder), a saber:

\begin{tabular}{|l|l|}
\hline \multicolumn{1}{|c|}{ Poder } & \multicolumn{1}{|c|}{ Funções } \\
\hline Executivo & $\begin{array}{l}\text { Realizar ações em beneficio da coletividade obedecendo as Leis } \\
\text { vigentes. }\end{array}$ \\
\hline Legislativo & $\begin{array}{l}\text { Através de representantes dos Estados Federados tem por objetivo criar } \\
\text { novas Leis, gerenciar as já existentes e fiscalizar o cumprimento da Lei e } \\
\text { a atuação por parte do Executivo, atendendo aos anseios e desejos do } \\
\text { povo que estes representam. }\end{array}$ \\
\hline Judiciário & $\begin{array}{l}\text { Responsável por sanar eventuais dúvidas surgidas na interpretação da } \\
\text { Lei, além de resolveram problemas surgidos baseados nos preceitos } \\
\text { estabelecidos em Lei. }\end{array}$ \\
\hline
\end{tabular}

\section{QUADRO 02 - Funções típicas dos três poderes.}

Todos estes poderes citados - Executivo, Legislativo e Judiciário - bem como todos os níveis de governo - Federal, Estadual, Municipal e o Distrito Federal - além das administrações diretas e indiretas, todos estes se caracterizam como Administração Pública e são regidos pelos princípios constitucionais e demais leis e normas estabelecidas na Constituição Federal de 1988.

\section{GOVERNO ELETRÔNICO (E-GOV)}

De acordo com os Portal do Governo Eletrônico Brasileiro ${ }^{1}$ :

As ações do E-gov priorizam o uso das tecnologias da informação e comunicação (TIC's) para o desenvolvimento da democracia do acesso à informação, visando ampliar o debate e a participação popular na construção das políticas públicas, como também aprimorar a qualidade dos serviços e informações públicas prestadas.

Nesse contexto, observa-se que uma das premissas do E-gov é democratizar o acesso à informação para a população, construindo e ampliando políticas públicas e otimizando a qualidade dos serviços oferecidos a todos os interessados.

Guilarducci (2007, p. 18) defini como:

O uso das tecnologias da informação e comunicação para garantir o cumprimento efetivo e eficiente dos princípios que legitimam o Governo constituída para o povo,

\footnotetext{
${ }^{1}$ Disponível em: www.governoeletronico.gov.br
} 
ou seja, é o uso das tecnologias da informação e comunicação para o cumprimento real das Leis que regem a nação.

Os princípios básicos da Administração Pública expressos explicitamente na Constituição Federal de 1988, são assegurados pelas ações de E-gov, pois, esse objetivo está intrínseco em seu conceito.

É importante destacar que E-gov não se caracteriza apenas por sites de internet, sendo restrito apenas ao Poder Executivo, este atinge todas as esferas da Administração Pública, estendendo-se aos três poderes, além da administração direta ou indireta no que tange o uso dos recursos de tecnologia da informação e comunicação para oferecer melhores serviços a população, otimizando seus processos internos e externos através de mecanismos eficientes, transparentes e seguros. Ainda, segundo o Portal do Governo Eletrônico Brasileiro "não se trata somente de colocar mais serviços disponíveis na Internet, mas de fazer com que a sua presença na Internet beneficie o conjunto dos cidadãos e promova o efetivo acesso ao direito aos serviços públicos".

Barbosa, Cappi e Gatto (2009) vão além e traçam a importância do E-gov em um contexto social, além da perspectiva dos governos para o futuro:

\begin{abstract}
Os governos dependem de componentes que sirvam de elo entre os serviços públicos e o cidadão. [...] A idéia de governo eletrônico está fortemente apoiada em uma nova visão do uso das tecnologias para a prestação de serviços públicos, mudando a maneira pela qual um governo interage com o cidadão, com empresas e com outros governos. O governo eletrônico favorece a melhoria dos serviços públicos e dos processos da Administração Pública, o aumento da eficiência, favorece a integração entre os órgãos do Governo, aumenta a transparência e fomenta a participação democrática.
\end{abstract}

Torna-se explicito a importância do E-gov para os governos e para sociedade como forma de melhorar os laços, aumentando a eficiência e transparência entre os serviços necessários, transformando o cidadão elo fundamental ao sucesso das ações adotadas, seguido pelas empresas e os próprios governos entre si.

\title{
HISTÓRICO
}

Os estudos e projetos acerca do E-gov surgiram em meados do ano 2000, através de um grupo formado por representantes de todos os Ministérios do Governo Federal, com a finalidade de observar as propostas e analisar as metas para os próximos anos, sendo este regulamentado por Decreto em 03 de Abril de 2000.

Desde então, surgiram novos documentos e normativas acerca do assunto, além do envolvimento direto do Ministério da Ciência e Tecnologia - MCT através do seu programa Sociedade da Informação que traçou metas a serem atingidas ao longo dos anos, concentrando esforços em três frentes distintas, segundo o Portal do Governo Eletrônico Brasileiro, a saber: universalização de serviços; governo ao alcance de todos e infra-estrutura avançada.

Ainda no ano 2000, o MCT lançou um documento denominado "Proposta de Política de Governo Eletrônico para o Poder Executivo Federal", em seguida, através de Decreto emitido em 18 de Outubro de 2000, foi criado o Comitê Executivo do Governo Eletrônico - CEGE, sendo este coordenado pelo Secretário Chefe da Casa Civil e membros de todos os Ministérios e órgãos da administração. O CEGE foi distribuído em Comitês que atuavam em diversas áreas e tinham objetivos diretos de concentrar esforços em áreas especificas. 
Em 2004 foi instituído o Departamento de Governo Eletrônico, vinculado ao Ministério do Planejamento, Orçamento e Gestão, regulamentado através do Decreto $n^{\circ} 5.134$, de 07 de julho de 2004. Este se tornaria o responsável pelas ações de planejamento, estudos e implantação do E-gov no Governo Federal, sendo posteriormente responsável por criar normas e padrões que possibilitassem a implantação de serviços em E-gov em todas as esferas e níveis hierárquicos da Administração Pública.

A partir de então, a cada ano tornaram-se mais consolidadas as propostas de E-gov no Brasil, através de ações e novos serviços baseados em TIC's que passaram a ser implantados em todos os setores, sendo estes adaptados às legislações e estas sendo adaptadas aos novos tempos que a gestão pública vivencia.

\section{TIPOS DE SERVIÇOS}

Os serviços de E-gov possuem três padrões de utilização distintas e variam de acordo com os objetivos almejados, bem como dos recursos disponíveis na internet para os clientes e fornecedores, além do nível de implantação naquele órgão. Estes tipos de serviços são diferentes, ou seja, determinado órgão pode oferecer um serviço que atenda apenas um, dois, os três padrões disponíveis ao mesmo tempo. Segundo Silva, Ribeiro e Rodrigues (2005, p. 201) os tipos de serviços oferecidos são:

\section{GOVERNO PARA O CIDADÃO (GOVERNMENT TO CITIZEN) - G2C}

Caracteriza-se pela oferta de serviços oferecidos, pela administração diretamente aos cidadãos, principalmente utilizando recursos de internet, pois possibilita o acesso a informações e serviços do governo em qualquer hora ou dia pela sociedade. Neste tipo de serviço, destacam-se serviços de realização de matrículas online, emissão de documentos fiscais, jurídicos, certidões, pagamentos de impostos, declaração de imposto de renda, programas de educação a distância e atualização de dados cadastrais.

De acordo com a pesquisa sobre o uso das TIC's no Brasil realizada anualmente pelo Comitê Gestor da Internet no Brasil - CGI, os principais serviços em E-gov utilizados pela população maior de 16 anos são: 49\% realizam consultas ao CPF; $41 \%$ buscam por informações sobre serviços públicos; $39 \%$ realizam inscrições em concursos públicos; $33 \%$ procuram vagas de trabalho; $27 \%$ buscam informações sobre direitos do trabalhador; $26 \%$ pesquisam sobre serviços públicos de saúde (Gráfico 01).

Através dos resultados da pesquisa, observa-se que os cidadãos estão utilizando principalmente serviços de consulta simples, buscando informações sobre algum tema específico. Executando tarefas que antes teriam a necessidade de realizar pessoalmente, dirigindo-se aos órgãos em questão, destacando a inscrição em um concursos públicos. 


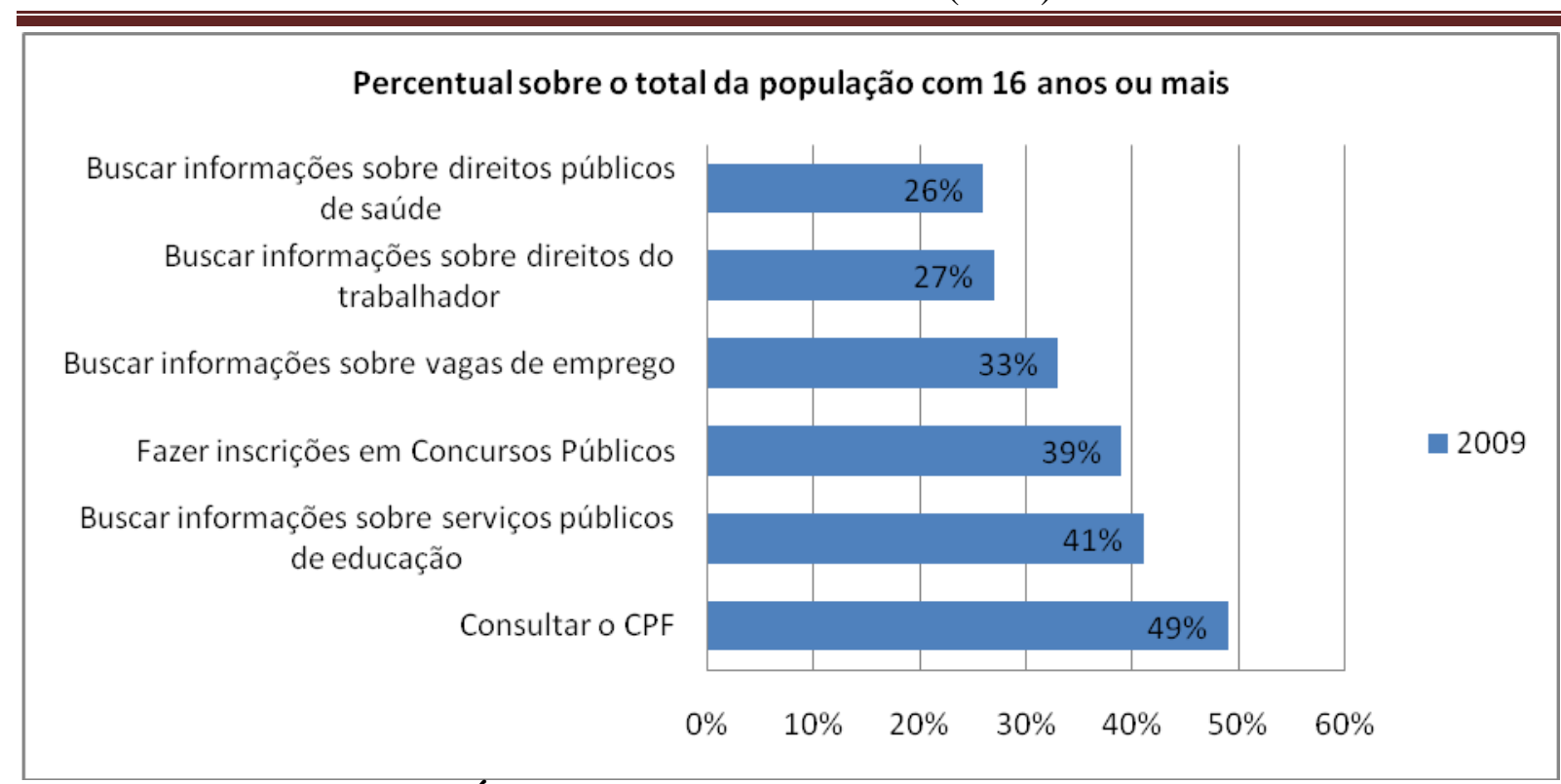

\section{GRÁFICO 01 - Serviços de E-gov utilizados Fonte: Comitê Gestor da Internet no Brasil, (2009)}

\section{GOVERNO PARA EMPRESAS (GOVERNMENT TO BUSINESS) - G2B}

Busca-se através dos G2B proporcionar uma evolução entre o relacionamento e as transações realizadas entre o governo e as empresas, sejam elas fornecedoras de bens ou serviços para os órgãos públicos, ou na relação de suas obrigações legais junto ao Governo, otimizando a relação de ambos os lados. Destaca-se a modernização das compras públicas, através de processos de Pregão Eletrônico e Compras-Online, desburocratizando a máquina pública em processos que eram lentos e ocorriam rotineiramente. Como também facilitando o acesso das empresas aos serviços do governo, que estas têm obrigação legal ou realizando consultas rotineiras, a saber: pagamentos de impostos, emissão de certidões, consultas a dados da previdência social e direitos do trabalhador, entre outros. Preservando sempre em todas as transações e consultas realizadas a segurança e confiabilidade devidas aos empreendedores que utilizam os serviços oferecidos.

Ainda, segundo a Pesquisa CGI realizada no ano de 2009, as empresas realizam transações ou consultas pela internet utilizando recursos de E-gov. No tocante às transações, $50 \%$ do total das empresas entrevistadas realizam algum pagamento de impostos ou taxas utilizando serviços de E-gov, enquanto que $26 \%$ cadastram-se e submetem-se a licitações através de Pregão Eletrônico disponibilizado pelas gestões (Gráfico 02). Quando trata-se apenas de consultas realizadas, a pesquisa revela que $62 \%$ consultam o Programa de Integração Social PIS, nesse caso empresas privadas; o Programa de Formação do Patrimônio do Servidor PASEP, para órgãos e empresas pública; e o Fundo de Garantia por Tempo de Serviço FGTS dos trabalhadores; $61 \%$ buscam informações sobre impostos diversos; e 60\% consultam o cadastro de inscrições estaduais (Gráfico 03). 


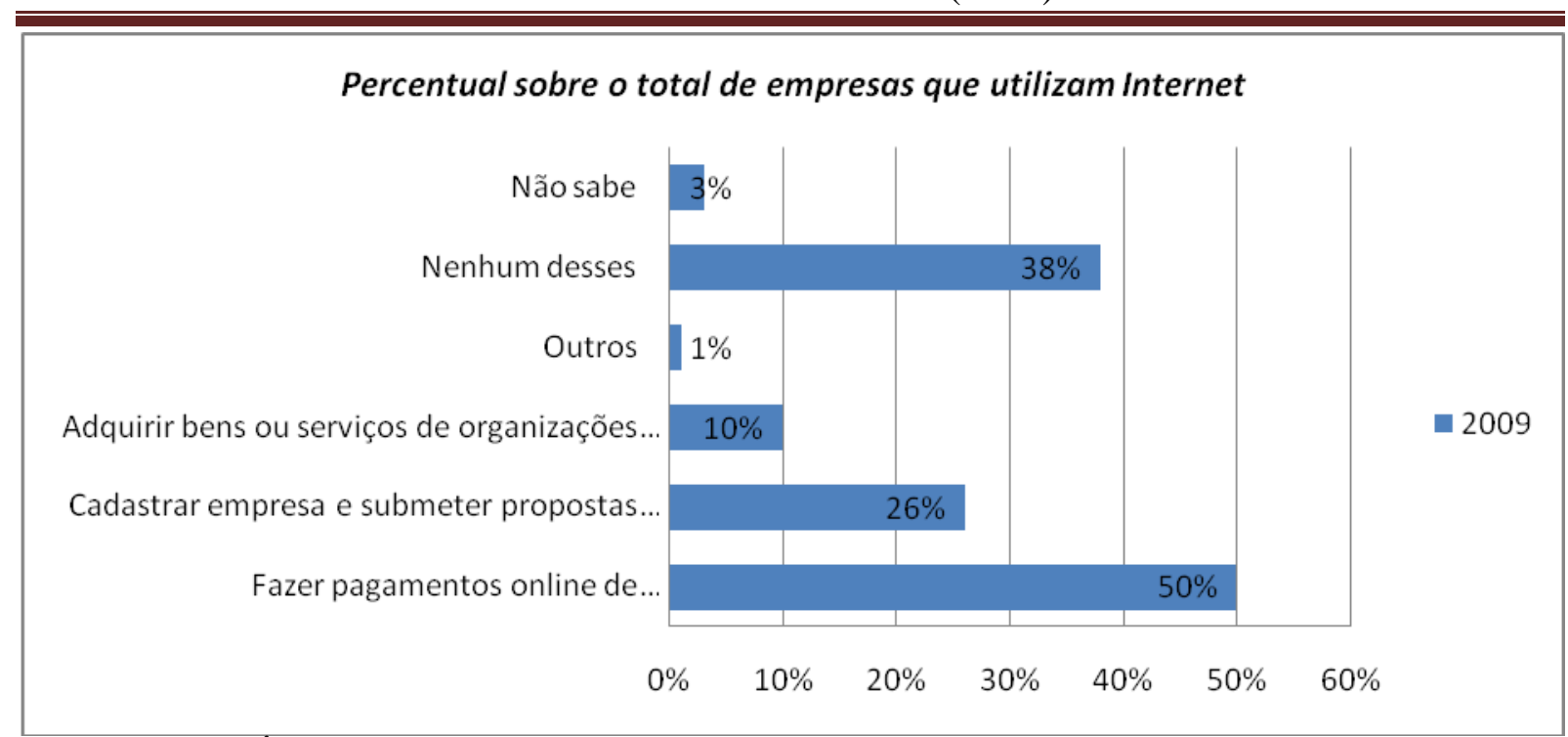

GRÁFICO 02 - Principais transações de E-gov realizadas na internet Fonte: Comitê Gestor da Internet no Brasil (2009)

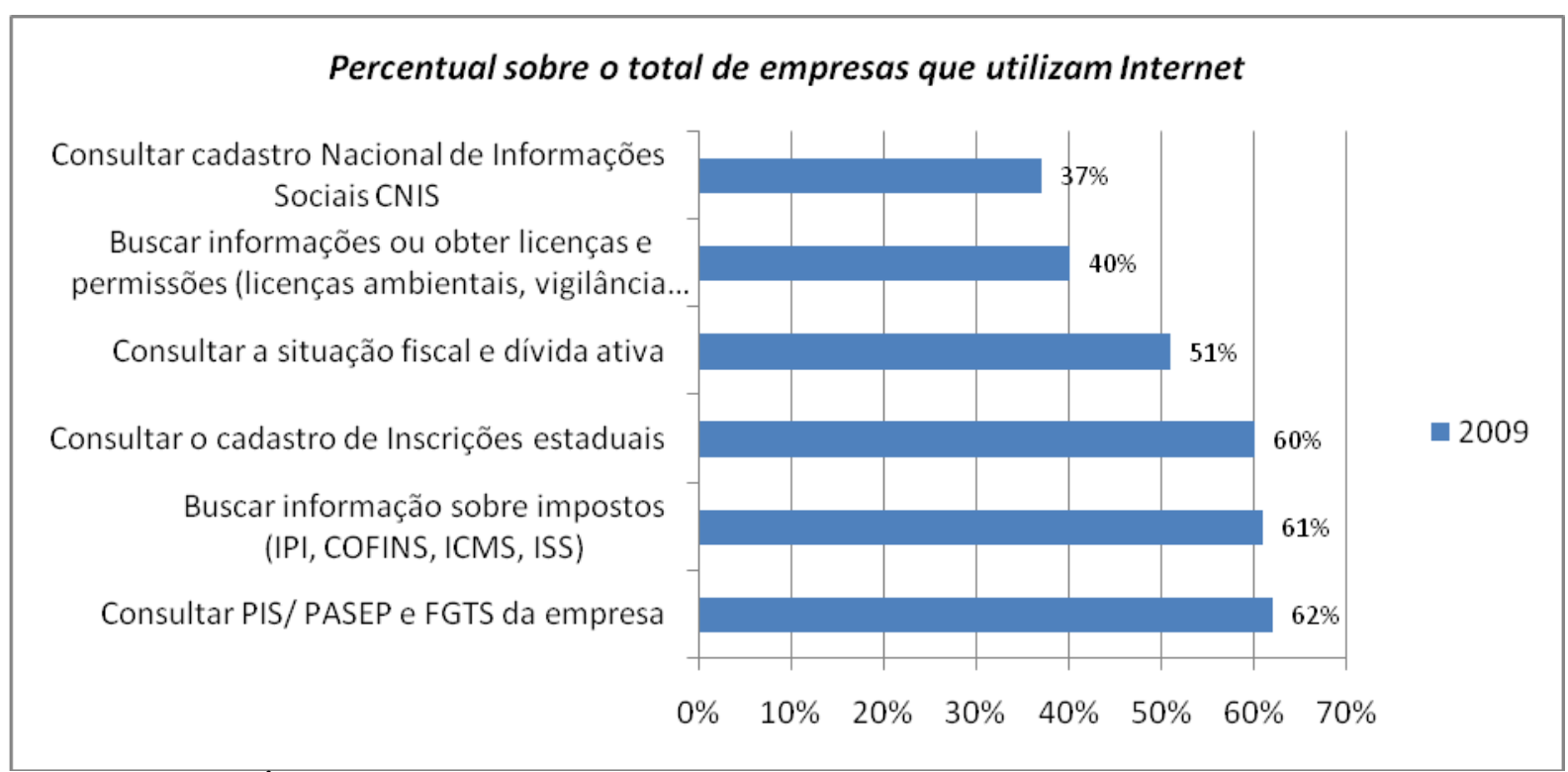

\section{GRÁFICO 03 - Principais consultas de E-gov realizadas na internet Fonte: Comitê Gestor da Internet no Brasil (2009)}

A partir dessas informações, é possível considerar a importância do E-gov para as organizações. Apesar destas realizarem mais consultas online, considera-se, segundo a pesquisa CGI, uma evolução para o setor no que diz respeito a transações, pois, em 2006, apenas 36\% pagavam taxas e impostos pela internet. Três anos depois esse número já atinge $50 \%$, caracterizando-se, assim, como um desenvolvimento significativo.

\section{GOVERNO PARA GOVERNO (GOVERNMENT TO GOVERNMENT) - G2G}

O foco norteador deste tipo de serviço E-gov é realizar uma perfeita e eficiente integração e realização de transações entre os governos, seja federal, estadual ou municipal, entres os poderes legislativo, executivo e judiciário, além da administração indireta, como forma de aprimorar as transações, diminuindo a burocracia, os custos e o tempo de tramitação dos processos, facilitando a comunicação entre gestões separadas por quilômetros de distância. Destaca-se a desburocratização para realização de convênios através do E-gov o Governo 
Federal e os Estados e Municípios; Além da melhoria entre os procedimentos administrativos que os níveis de governo têm que manter com os demais órgãos. Nesse sentido muitos sistemas online que visam otimizar processos e melhorar comunicações são utilizados por toda a administração, aumentando a eficiência do serviço público em todas as suas áreas.

O E-gov utiliza recursos de internet, intranet e extranet, como forma de promover uma ligação entre os diversos órgãos e setores da Administração Pública. Dessa maneira, os servidores são diretamente beneficiados pelos serviços que visam facilitar o desempenho e a qualidade dos trabalhos realizados em todos os departamentos de qualquer órgãos público, através de sistemas que integram as tarefas rotineiras realizadas e desburocratizam de maneira segura os serviços prestados, aumentando a eficiência.

\section{ESTÁGIOS}

As atividades e ações do E-gov possuem quatro estágios evolutivos (Figura 01) que norteiam a qualidade e nível de implantação das TIC's nos Governos. Descrevendo quais as funções que devem está disponíveis em cada nível, sendo possível inclusive, identificar quantos estágios as cidades, estados ou o país estão cumprindo ao mesmo tempo, frente as novas tecnologias e níveis de implantação e aceitabilidade pelas diversas esferas e poderes da Administração Pública Federal, Estadual ou Municipal. Servindo também para definir de fato qual o papel do E-gov na gestão pública e o que a sociedade deve aguardar de ações por parte dos governantes.

Silva, Ribeiro e Rodrigues (2005) enumeram os quatro estágios de forma sucinta e esclarecedora, a saber:

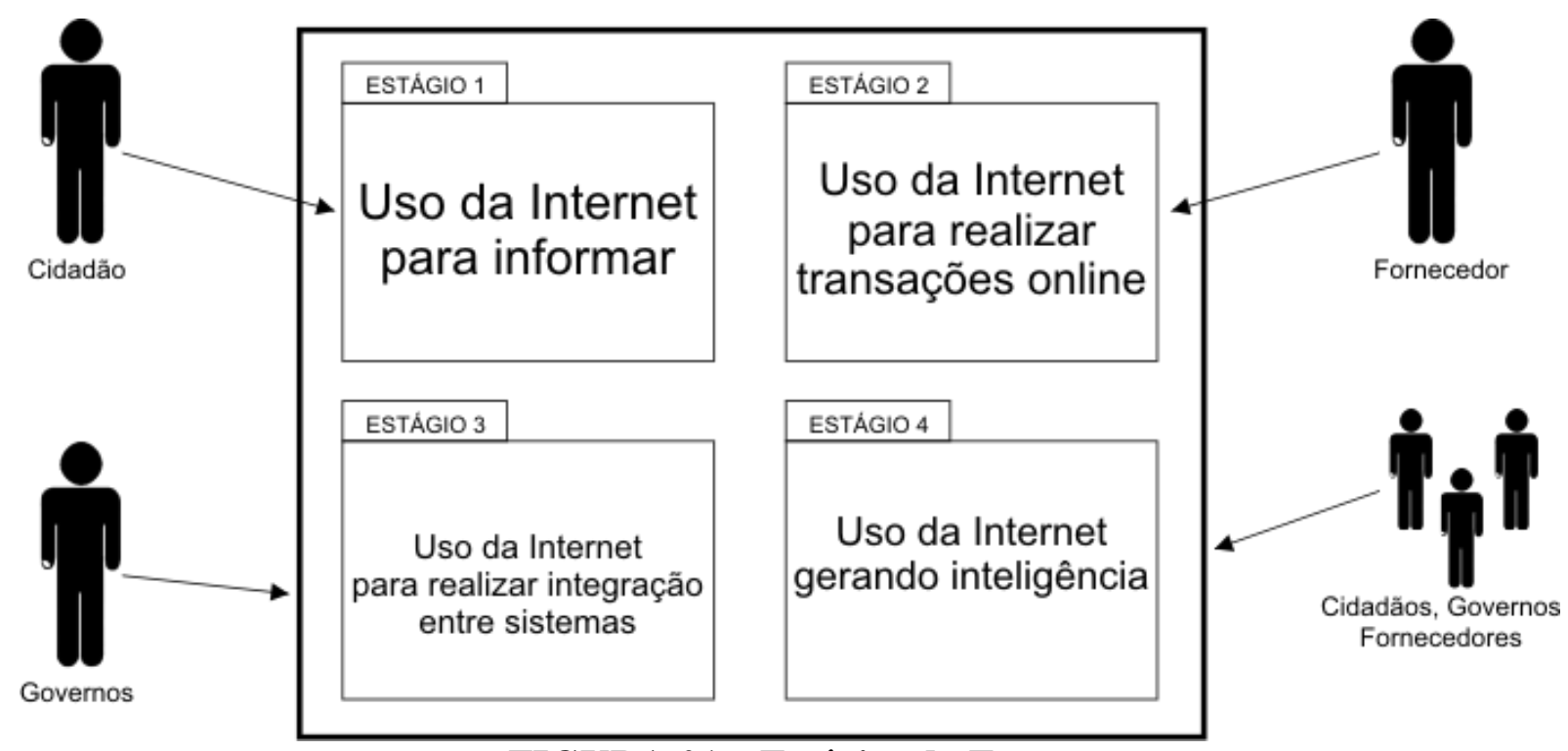

FIGURA 01 - Estágios do E-gov

Adaptado de Silva, Ribeiro e Rodrigues (2005, p. 201)

\section{ESTÁGIO 1}

Nesta etapa são utilizados sites institucionais simples, servindo apenas para disponibilizar informações sobre a administração, suas ações e serviços realizados, sobre a localidade e sua localização, seja na administração direta ou indireta. Caracteriza-se como o serviços mais básico do E-gov, pois, proporcionar a comunidade conhecer os trabalhos executados de forma acessível é um dos serviços mais simples que o E-gov pode proporcionar. 
Contudo, observa-se que muitos municípios brasileiros ainda não dispõem sequer de um site institucional disponibilizando as informações básicas da cidade, estando estes, fora de um mundo onde as TIC's estão presentes na vida das pessoas a todo momento e que essa dependência tende a aumentar cada vez mais.

A Pesquisa de Informações Básicas Municipais 2009 realizada anualmente pelo Instituto Brasileiro de Geografia e Estatística - IBGE revela que 60\% das Prefeituras, já disponibilizam aos cidadãos site institucional; $15 \%$ estão em construção e $25 \%$ não dispõem destes recursos (Gráfico 04).

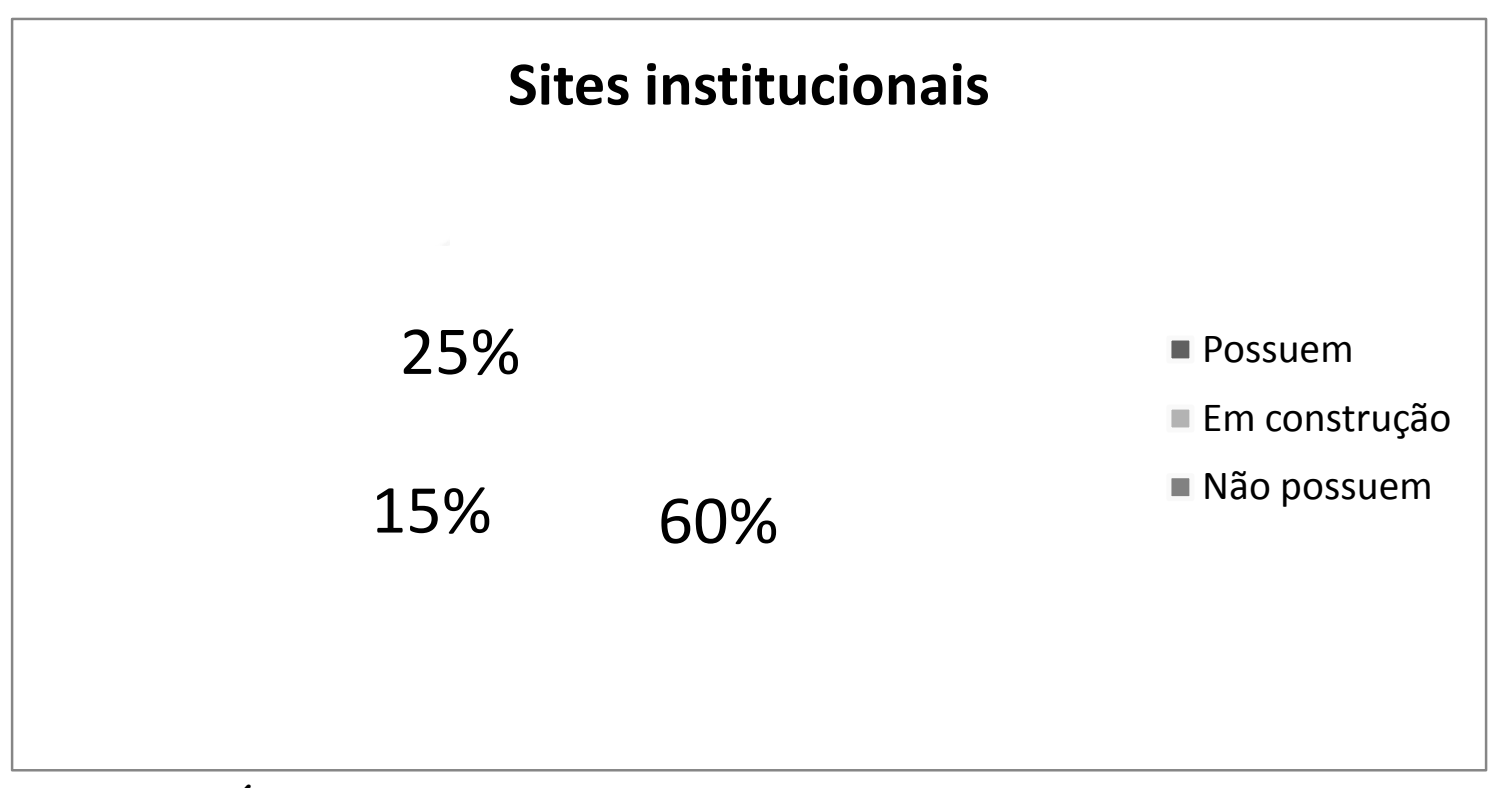

\section{GRÁFICO 04 - Municípios com página na Internet da prefeitura Adaptado da Pesquisa de Informações Básicas Municipais 2009 (IBGE)}

Esses números demonstram um avanço, porem, ainda revela um elevado numero de cidades que não disponibilizam aos cidadãos o mínimo de utilização das TIC's para ações de E-gov.

Do total de cidades que não possuem paginas institucionais de internet, cerca de $95 \%$ destas são municípios com população inferior a 50 mil habitantes, segundo ainda a pesquisa do IBGE. Estas que não possuem sequer um site institucional e não cumprem o Estágio 1 aqui descrito, não estão ainda atentas para a revolução que o E-gov pode proporcionar no ponto de vista das tecnologias auxiliando a gestão e melhorando relações com os cidadãos e com as empresas.

\section{ESTÁGIO 2}

As transações realizadas on-line são enfatizadas nesta fase, ou seja, os sites simples contendo apenas informações sobre a gestão, evoluem e passam a possibilitar realização de transações pela internet, eliminando a burocracia característica da Administração Pública, diminuindo custos e aumentando a eficiência através de sistemas eficientes que garantem o cumprimento dos princípios constitucionais da gestão pública.

A pesquisa de Informações Básicas Municipais (IBGE, 2009) revela ainda que dos 3,339 municípios que dispõem de pagina institucional: $45 \%$ dispõem apenas de um site simples, apenas disponibilizando informações básicas aos cidadãos; 32\% realizam algum tipo de interação, seja fóruns, enquetes ou downloads; e $23 \%$ realizam alguma transação de fato com a sociedade. Estes realizam ações do tipo G2C e G2G - Governo para o Cidadão e Governo para Empresas respectivamente, e destaca-se a possibilidade de emissão de documentos, 
alvarás, matriculas, contra-cheques e ainda em casos mais evoluídos a realização de processos de licitação, cotação de preços e compras através da internet, aumentando a concorrência, diminuindo os prazos e possibilitando que empresas de qualquer parte do país participem. Esses dados são destacados no Gráfico 05.

\section{Sites institucionais}

$23 \%$

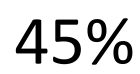

- Informativa

Interativa

Transacional

$32 \%$

\section{GRÁFICO 05 - Serviços disponíveis nas páginas na Internet das Prefeituras Adaptado da Pesquisa de Informações Básicas Municipais 2009 (IBGE)}

O gráfico revela um baixo numero de municípios que realizam alguma transação de fato através da página institucional em ações E-gov, contudo, demonstra um avanço se comparado a dados da mesma pesquisa de 2005 .

Sendo importante ressaltar ainda, que as transações citadas na pesquisa, incluem apenas aquelas de autoria do próprio município, ou seja, se reunir diversos serviços disponibilizados por outros órgãos e inseri-los através de link na pagina da prefeitura, não se caracteriza como realização de transações por parte da prefeitura.

\section{ESTÁGIO 3}

A integração entre os sistemas dos Governos é posta em foco nesta etapa, onde o tipo de serviço predominante é o Governo para Governo - G2G. Busca-se, então, realizar uma integração necessária entre os diversos SI dos governos, seja municipal, estadual ou federal, além dos poderes legislativo, executivo e judiciário. Através da integração desses sistemas é diminuído a burocracia existente garantindo serviços legais, impessoais, morais, públicos e eficientes, cumprindo, dessa forma, os princípios constitucionais da Administração Pública e oferecendo serviços de qualidade, seja aos cidadãos, aos fornecedores ou mesmo entre os diversos níveis de governo.

\section{ESTÁGIO 4}

Busca-se criar um ambiente colaborativo que gere inteligência, ou seja, que a sociedade em geral possa opinar, criar e originar uma evolução positiva e gradativa de diversos aspectos e assuntos que as envolvam. A colaboração da sociedade de forma espontânea e criativa são destaque nesta etapa. 
Através de fóruns, enquetes, sites que possibilitam que o usuário interaja dinamicamente, expressando sua opinião sobre algum tema especifico, opinando de fato, realizando consultas públicas através de recursos vinculados as TIC's.

O Estágio 4 aumentará sua atuação quando os outros já estiverem bem evoluídos e intrínsecos a população, as empresas e difundido ainda dentro da própria Administração Pública de forma mais consolidada.

\section{EM QUE ESTÁGIO ESTAMOS}

Baseado na pesquisa do IBGE e relacionando com os Estágios aqui descritos, é possível destacar que as ações E-gov estão concentradas principalmente no Poder Executivo Federal e em todas as suas vertentes, além dos Legislativo e Judiciário, nas empresas públicas e demais órgãos da administração indireta, nos estados e nas capitais e grandes cidades brasileiras. Estes disponibilizam serviços E-gov de forma mais aprofundada e concreta, atendendo principalmente aos estágios 1, 2 e 3 concomitantemente, sendo esta realidade uma evolução para a sociedade brasileira e para o país como um todo. O Estágio 4 ainda está na sua fase inicial no Brasil, apenas alguns Ministérios do Governo Federal já dispõem de algum serviço parecido com os descritos na fase 4 .

Apenas os pequenos municípios brasileiros estão atrasados no desenvolvimento de ações Egov de sua própria autoria, contudo, estes utilizam rotineiramente serviços em suas atividades disponibilizados por órgãos ou setores que mantêm relações com os municípios e que modernizaram seus processos. Destacando o Governo Federal ou Estadual, principalmente em ações como submissão de projetos, pesquisas, fornecimento de dados, execução de obras, prestação de contas, seguridade social, pagamento de tributos, entre outros.

\section{EXEMPLOS E-GOV DE SUCESSO}

As ações E-gov estão evoluindo fortemente, através de novos serviços e recursos espalhados por todas as vertentes da Administração Pública, em todos os seus poderes e níveis do governo. Dessa maneira o Quadro 04 apresenta um resumo das ações e programas citados neste estudo, exibindo quem é o órgão responsável pela idéia, quem são os reais beneficiários e ainda o tipo de serviço e estágios que estes se encontram, a saber: 


\begin{tabular}{|c|c|c|c|c|}
\hline $\begin{array}{c}\text { Sistema/Ação E- } \\
\text { gov }\end{array}$ & Desenvolvido por & Beneficiados & $\begin{array}{c}\text { Tipo } \\
\text { de } \\
\text { Serviço }\end{array}$ & Estágios \\
\hline $\begin{array}{ll}\text { Projeto } & \text { PC } \\
\text { Conectado } & \end{array}$ & $\begin{array}{l}\text { Ministério da Ciência } \\
\text { e Tecnologia }\end{array}$ & - População em geral & $\mathrm{G} 2 \mathrm{C}$ & 1 \\
\hline Proinfo & $\begin{array}{l}\text { Ministério da } \\
\text { Educação }\end{array}$ & $\begin{array}{l}\text { - Comunidade, } \\
\text { - Professores, } \\
\text { - Alunos } \\
\text {-Equipe das escolas } \\
\text { públicas }\end{array}$ & $\mathrm{G} 2 \mathrm{C}$ & 1 \\
\hline $\begin{array}{l}\text { Programa Banda } \\
\text { Larga nas Escolas }\end{array}$ & $\begin{array}{l}\text { Ministério da } \\
\text { Educação }\end{array}$ & $\begin{array}{l}\text { - Comunidade, } \\
\text { - Professores, } \\
\text { - Alunos } \\
\text { - Equipe das escolas } \\
\text { públicas }\end{array}$ & $\mathrm{G} 2 \mathrm{C}$ & 1 \\
\hline Gesac & $\begin{array}{l}\text { Ministério da } \\
\text { Educação }\end{array}$ & $\begin{array}{l}\text { - Comunidade, } \\
\text { - Professores, } \\
\text { - Alunos } \\
\text { - Equipe das escolas } \\
\text { públicas }\end{array}$ & $\mathrm{G} 2 \mathrm{C}$ & 1 \\
\hline $\begin{array}{l}\text { Telecentro } \\
\text { Comunitário }\end{array}$ & $\begin{array}{l}\text { Ministério das } \\
\text { Comunicações }\end{array}$ & $\begin{array}{l}\text { - Comunidades rurais e } \\
\text { urbanas } \\
\text { - aldeias indígenas }\end{array}$ & $\mathrm{G} 2 \mathrm{C}$ & 1 \\
\hline $\begin{array}{l}\text { Programa Cidade } \\
\text { Digital }\end{array}$ & $\begin{array}{c}\text { Ministério das } \\
\text { Comunicações e } \\
\text { Secretarias Estaduais }\end{array}$ & $\begin{array}{l}\text { - População das cidades } \\
\text { atendidas }\end{array}$ & $\mathrm{G} 2 \mathrm{C}$ & 1 \\
\hline Siconv & $\begin{array}{c}\text { Ministério do } \\
\text { Planejamento, } \\
\text { Orçamento e Gestão }\end{array}$ & $\begin{array}{l}\text { - Prefeituras e } \\
\text { - Governos Estaduais }\end{array}$ & $\begin{array}{l}\mathrm{G} 2 \mathrm{C} \\
\mathrm{G} 2 \mathrm{G}\end{array}$ & $1,2,3$ \\
\hline $\begin{array}{ll}\text { Portais } & \text { da } \\
\text { Transparência } & \end{array}$ & $\begin{array}{l}\text { Controladoria Geral } \\
\text { da União }\end{array}$ & - Sociedade em geral & $\begin{array}{l}\mathrm{G} 2 \mathrm{C} \\
\mathrm{G} 2 \mathrm{~B}\end{array}$ & 1 \\
\hline SIAFI & $\begin{array}{l}\text { Ministério da } \\
\text { Fazenda }\end{array}$ & $\begin{array}{l}\text { - Prefeituras e } \\
\text { - Governos Estaduais }\end{array}$ & $\mathrm{G} 2 \mathrm{G}$ & $1,2,3$ \\
\hline Educacenso & $\begin{array}{l}\text { Instituto Nacional de } \\
\text { Estudos e Pesquisas } \\
\text { Educacionais - INEP } \\
\end{array}$ & - Ministério da Educação & $\mathrm{G} 2 \mathrm{G}$ & $1,2,3$ \\
\hline Sistemas de Seleção & $\begin{array}{l}\text { Ministério da } \\
\text { Educação }\end{array}$ & $\begin{array}{l}\text { - Ministério da Educação } \\
\text { - Estudantes } \\
\text { - Universidades }\end{array}$ & $\begin{array}{l}\mathrm{G} 2 \mathrm{C} \\
\mathrm{G} 2 \mathrm{G}\end{array}$ & $1,2,3$ \\
\hline Cad-Único & $\begin{array}{l}\text { Ministério do } \\
\text { Desenvolvimento } \\
\text { Social }\end{array}$ & $\begin{array}{l}\text { - Beneficiários do Bolsa } \\
\text { Família } \\
\text { - Secretarias Estaduais } \\
\text { - MDS } \\
\text { - CEF }\end{array}$ & $\begin{array}{l}\mathrm{G} 2 \mathrm{C} \\
\mathrm{G} 2 \mathrm{G}\end{array}$ & 3 \\
\hline $\begin{array}{l}\text { Portais do Poder } \\
\text { Legislativo }\end{array}$ & $\begin{array}{c}\text { Senado Federal, } \\
\text { Câmara dos } \\
\text { Deputados Federais e } \\
\text { Estaduais } \\
\end{array}$ & - População em geral & $\mathrm{G} 2 \mathrm{C}$ & 1 \\
\hline $\begin{array}{l}\text { Portais do Poder } \\
\text { Judiciário }\end{array}$ & $\begin{array}{c}\text { Tribunais Regionais e } \\
\text { Federal }\end{array}$ & - População em geral & $\begin{array}{l}\mathrm{G} 2 \mathrm{C} \\
\mathrm{G} 2 \mathrm{G}\end{array}$ & 1,2 \\
\hline
\end{tabular}

QUADRO 04 - Resumo ações E-gov 
Diante dessas informações, constata-se que o E-gov encontra-se difundido em todos os níveis e poderes da Administração Pública, ao ponto que, cada órgão tenta através das TIC's melhorar seus serviços por meio de soluções inovadoras que garantam toda a credibilidade necessária a gestão pública, prezando por seus princípios básicos, além da transparência necessária. Realizando ainda, uma desburocratização positiva, onde todos tendem a ganhar.

Contudo, ainda há muito a ser evoluído com relação ao E-gov, sendo que os exemplos citados, servem para mostrar a importância dos que já vem sendo feito e abrir horizontes para o que ainda há de vir.

\section{CONSIDERAÇÕES FINAIS}

E-gov é a utilização das TIC's visando uma melhoria nos serviços públicos, tornando estes mais acessíveis a população de todas as classes sociais, melhorando a relação com organizações privadas, além de uma integração entre os diversos poderes e esferas do governo. Gerando assim, uma maior eficiência, transparência e segurança nas atividades desenvolvidas, desburocratizando positivamente a máquina pública.

No Brasil, o E-gov está evoluindo em ritmo acelerado, sendo que diversos novos recursos e facilidades são implantadas regularmente, principalmente, pelo Poder Executivo. Contudo, os demais Poderes - Legislativo e Judiciário - também possuem bons exemplos de ações positivas que otimizaram as rotinas e tarefas executadas. A utilização das TIC's pela Administração Pública, requer planejamento e estudos no processo de implantação, buscando dessa maneira tornar as atividades mais eficientes, evitando transtornos no processo de transição inicial.

Porém, constata-se que o ritmo de crescimento do E-gov não está na mesma velocidade em todas as vertentes da área pública, pois, principalmente os municípios com população inferior a 50 mil habitantes ainda não observaram os benefícios que essas novas funcionalidades podem proporcionar a gestão e a sociedade. Muitos destes não possuem sequer um site institucional fornecendo as informações básicas do cidade. Mesmo assim, eles não estão totalmente excluídos digitalmente, pois, utilizam os serviços desenvolvidos por outros órgãos da administração pública e também participam dos benefícios dos novos recursos oferecidos, já que suas atividades são facilitadas.

Provavelmente, os gestores dessas localidades não invistam em tecnologia, especificamente em E-gov, por imaginarem que os custos são elevados ou por não possuírem mão-de-obra qualificada, e ainda, por simplesmente não reconhecerem as TIC's como um facilitador na melhoria dos serviços públicos.

Um olhar mais empreendedor poderia solucionar o problema dos pequenos municípios brasileiros e tornarem estes, não apenas usuários dos recursos de outros órgãos, como também, criadores de ferramentas que desburocratizem as dificuldades daquela cidade especificamente. Criação de consórcios com outras Prefeituras, visando diminuir os custos na criação de novas ferramentas que sirvam para várias cidades que apresentam as mesmas necessidades. Ou ainda, contratação de profissionais terceirizados ou qualificação de servidores, ajudariam a facilitar o processo de inserção das localidades na era digital.

O E-gov como fator de ampliação da atuação da Administração Pública, não pode dividir a sociedade em duas: as detentoras de recursos de TIC's e aquelas excluídas digitalmente. Deve-se então, realizar um trabalho de democratização dos recursos tecnológicos, buscando dessa forma fazer com o Governo chegue em todas as localidades do Brasil de forma efetiva. 
Muitas ações já são executadas, mas, estas devem ser ampliadas e transformadas em política de governo.

É inquestionável que está acontecendo uma evolução na Administração Pública, pois, através do E-gov é possível ampliar a ação dos governos, chegando a todos os brasileiros. Melhorando também a relação com empresas e fornecedores e com as outras esferas da administração. Todos esses benefícios agregados ao fato das ações prezarem por transparência, eficiência e publicidade, gera uma desburocratização positiva para todos que se relacionam com órgãos públicos. Possibilita também, que a população - agora mais atuante possa fiscalizar, cobrar e expor seus pensamentos através desses nossos recursos.

Todos esses benefícios citados, são constatados através dos exemplos expostos neste trabalho e servem para fortalecer o conceito de E-gov, demonstrando em casos práticos a qualidade dos serviços oferecidos e os reais benefícios que estes trouxeram a população.

Mesmo com uma grande quantidade de casos de sucesso em E-gov disponíveis pelos órgãos públicos, é fato que, o Brasil ainda encontra-se em um nível inicial de desenvolvimento, sendo ainda este tema importante para futuras pesquisas e exposições, inserindo a academia no debate deste importante acontecimento para o Brasil como um todo.

Conclui-se então, que através do E-gov é possível transformar a Administração Pública positivamente, através de mecanismos que garantam eficiência, transparência, melhorando relações com empresas, outros níveis de governo e principalmente democratizando os serviços públicos para o cidadão.

\section{REFERÊNCIAS}

1. ALEXANDRINO, Marcelo. PAULO, Vicente. Direito Administrativo Descomplicado. $17^{\text {a }}$ Ed. - Rio de Janeiro: Forense. São Paulo: Método, 2009.

2. BARBOSA, Alexandre Fernandes; CAPPI, Juliano; GATTO, Raquel. Os caminhos para o avanço do governo eletrônico no Brasil. In: CGI.br (Comitê Gestor da Internet no Brasil). Pesquisa sobre o uso das tecnologias da informação e comunicação 2008. São Paulo, 2009, pp.67-71.

3. BRASIL. Constituição (1988). Constituição da República Federativa do Brasil: promulgada em 5 de outubro de 1988. 23 ${ }^{\text {a }}$ Ed. - Brasília: Câmara dos Deputados, Coordenações de Publicações, 2004.

4. COMITÊ GESTOR DA INTERNET NO BRASIL - CGI. Pesquisa sobre o uso das tecnologias de informação e comunicação no Brasil - TIC Domicílios e TIC Empresas 2009. Núcleo de Informação e Comunicação do Ponto BR. São Paulo, 2010.

5.

Pesquisa sobre o uso das tecnologias de informação e comunicação no Brasil - TIC Domicílios e TIC Empresas 2005. Núcleo de Informação e Comunicação do Ponto BR. São Paulo, 2006.

6. GUILARDUCCI, Renato Vieira. E-gov: para que e para quem?. 2007. 63f. Dissertação (Graduação em Ciência da Computação) Instituto de Computação Universidade Federal Fluminense, 2007. Disponível em: http://portal.crie.coppe.ufrj.br/portal/data/

documents/storedDocuments/Egov_Para_que_e_para_quem.pdf. Acesso em: 13 de Outubro de 2010. 
7. INSTITUTO BRASILEIRO DE GEOGRAFIA E ESTATÍSTICA - IBGE. Pesquisa de Informações Básicas Municipais 2009 Disponível em: http://www.ibge.gov.br /home/estatistica /economia /perfilmunic/2009/default.shtm. Acesso em: 25 Out. 2010.

8. MEDAUAR, Odete. Direito Administrativo Moderno. De acordo com a EC 19/98. $4^{\mathrm{a}}$ Ed. - São Paulo: Editora Revista dos Tribunais, 2000.

9. MEIRELlES, Hely Lopes. Direito Administrativo Brasileiro. $28^{a}$ Ed. São Paulo: Malheiros Editores, 2004.

10. MORAES, Alexandre de. Direito Constitucional Administrativo. São Paulo: Atlas Editora, 2009.

11. SERESUELA, Nívea Carolina de Holanda. Princípios constitucionais da Administração Pública. Jus Navigandi. Teresina, ano 7, $n^{\circ}$ 60, 2002. Disponível em: <HTTP://jus2.uol.com.br/doutrina/texto.asp?id=3489>. Acesso em: 10 de Setembro de 2010.

12. SILVA, Arídio; RIBEIRO, Araújo; RODRIGUES, Luiz. Sistemas de Informação na Administração Pública. - $1^{\text {a }}$ Ed. - Rio de Janeiro, Renam - 2004. 